July - 2019

\title{
Understanding the Early Adjustment Experiences of Undergraduate Distance Education Students in South Africa
}

Dr Jenna Mittelmeier ${ }^{1}$, Dr Jekaterina Rogaten², Dr Dianne Long ${ }^{3}$, Dr Mwazvita Dalu ${ }^{4}$, Prof Ashley Gunter ${ }^{5}$, Prof Paul Prinslo0 ${ }^{6}$, and Prof Bart Rienties ${ }^{7}$

${ }^{1}$ The University of Manchester, 2,7The Open University, ${ }^{3}$ University of Witwatersrand, 4,5,6University of South Africa

\begin{abstract}
Much research in face-to-face contexts outlines the importance of early adjustment on students' higher education experiences. However, few studies have replicated this research in distance learning contexts to unpack the early multifaceted adjustments associated with studying in absence of a physical campus. This is particularly needed from a Global South perspective, where countries like South Africa have become regional hubs for distance learners. To explore distance learners' adjustment experiences, this study analysed results from a Student Adaptation to College Questionnaire (SACQ) with 320 distance learners at the University of South Africa, mixed with qualitative thematic analysis of open-ended questions. The results outlined key factors that impact distance learning experiences for students in South Africa, including demographic variables, class, language, and access to resources. These findings, compared with similar work in face-to-face contexts, suggest areas in need of additional support from distance education providers in South Africa and beyond.
\end{abstract}

Keywords: Distance education, higher education, student adjustment, South Africa 


\section{Introduction}

Early experiences in higher education, such as during the first year of study or in the first course units, are particularly influential on students' success and attrition (Wilcox, Winn, \& Fyvie-Gauld, 2005). While research on this topic tends to focus on face-to-face contexts, there has been increasing interest in early experiences in distance learning (Baxter, 2012; Brown, Hughes, Keppell, Hard, \& Smith, 2015). This emergent body of research is particularly valuable, since notions of what the label first year means for flexible distance programmes may vary from typical face-to-face contexts (Baxter, 2012). However, empirical findings on this phenomenon are scarce, particularly from a Global South perspective, where distance learning is gaining popularity (Subotzky \& Prinsloo, 2011). As such, an understanding of students' early adjustment experiences in distance learning contexts-defined as students' ability to cope with the multifaceted changes and stressors in their lives as a result of higher education study (Baker \& Siryk, 1999; Tinto, 1998)—can provide particularly useful insights into support mechanisms necessary for success.

To address this, we focused on the adjustment experiences of distance learners in a first-year course unit at the University of South Africa (UNISA), which is one of the largest distance education providers in the world. Within the broader context of South African public higher education, success and retention are major concerns, particularly at UNISA with its large student numbers (Department of Higher Education and Training, 2012). While research into early student experiences is well-established in the South African higher education context generally (e.g., Kahu \& Nelson, 2018), the specific context of distance education is still an emerging focus (e.g., Mahlangu \& Fraser, 2017). As such, this study explored the factors impacting students' distance learning adjustment experiences through a mixed methods questionnaire of 320 students at UNISA, providing a clearer understanding of distance learners' firstyear experiences.

\section{Literature Overview}

\section{Adjustment Experiences in Distance Education}

A wide variety of literature from around the world outlines that adjustment to the multifaceted transitions associated with higher education study impacts student success (Credé \& Niehorster, 2012). The early models of Spady (1970), Tinto (1975), and others attempted to map not only the role of variables that may impact students' decisions to continue with their studies or to drop out, but also how these variables intersect, and whether they are interdependent or mutually constitutive. Indeed, research on success and retention in higher education, and more specifically distance education, includes a range of approaches and perspectives (Subotzky \& Prinsloo, 2011).

Of specific interest to those researching students' early experiences in distance education is the notion that it is possible to cluster the various factors that impact success "at three related levels: individual (academic and attitudinal attributes, access to resources, and other personal characteristics and circumstances), institutional (quality and relevance of academic, non-academic, and administrative services), and supra-institutional (macro-political and socio-economic factors)" (Subotzky \& Prinsloo, 2011, p. 179). It is, therefore, crucial to remember that students' experiences will be impacted at all three levels. For example, some of the published research on South African distance education outlines issues such as access to materials and resources (Halabi, Essop, Carmichael, \& Steyn, 2014; Swart, 2015), developing social connections among students from different geographical contexts (Meier, 2007), and 
synchronous versus asynchronous activity offerings (Olivier, 2016). However, there are relatively few studies that have replicated research specifically into student adjustment in distance learning contexts, which arises in combination or as a result of these factors.

In the research on student adjustment, it is evident that the first year of study is particularly influential, as outlined by early research in face-to-face settings (Tinto, 1998; Upcraft \& Gardner, 1999). In the South African higher education context, the experiences of first-year students have gained considerable traction (Leibowitz, Van der Merwe, \& Van Schalkwyk, 2009). For example, McGhie (2017) described factors impacting students' experiences, including preparation for university coursework, workload, overcrowded timetables, and having (or not) the necessary social and academic capital to develop personal strategies to overcome these challenges. Similarly, Lekena and Bayaga (2018) noted that over "50 per cent of students, typically those from low-income or deprived circumstances, drop out due to financial struggles to carry the direct and indirect costs of university attendance" (p. 157). Other factors influencing the first-year experience in South Africa include family and support structures (Daniels, 2017), tutors (McKay, 2016), support services (Jordaan, 2016), and higher-order thinking skills (Faragher \& Huijser, 2014).

Yet to the best of our knowledge, outside of the research of McKay (2016) that focuses on the role of tutors in first-year experiences in distance education, there is no systematic research on students' early experiences in South African distance education. This represents a major gap in current knowledge, considering the high level of distance education enrolment, and unique social and political contexts in South Africa. These considerations are highlighted next.

\section{The South African and UNISA Contexts}

South African public higher education faces many of the obstacles seen elsewhere, including massification, funding regime changes, and changing student profiles (Altbach, Reisberg, \& Rumbley, 2009). However, also present is the impact of intergenerational legacies of colonialism and apartheid on public higher education (Badat, 2005), which has had profound implications for access to higher education as well as the resources required to study successfully. In this sense, South African higher education is "sandwiched between systemic contextual problems inherited from past educational policies . . . and a generation of limitless possibilities" (Bozalek \& Ngambi, 2015, p. 3). It would, therefore, be disingenuous to consider the students' experience at one particular distance education provider in South Africa without considering that we are "condemned to context" (Tessmer \& Richey, 1997, p. 88).

Distance education functions as a substantial subsystem in South African higher education, contributing up to $40 \%$ of higher education students (Department of Higher Education and Training, 2014). Until 2013, UNISA was the only higher education institution in South Africa licenced to offer distance education and, in response, it grew into a mega-university with almost 360,000 students. While there are 23 public universities in South Africa, UNISA hosts almost 300,000 more students than any other South African institution.

Despite this large student cohort, the institution only graduates approximately 30,000 students a year (i.e., less than $10 \%$ ), which suggests that many students experience challenges. In light of this, the specific academic, social, and emotional experiences of students at UNISA are of concern. In particular, 
research is needed to unpack why some students in South African distance education succeed while others struggle.

\section{Conceptual Framework}

Literature around the world has focused on how transitions throughout the higher education experience impact student success (Credé \& Niehorster, 2012). Seminal to this discussion is the work of Tinto (1975, 1998), who argued that higher education students' academic and social adjustments could explain differences in degree outcomes. Baker and Siryk (1999) built upon this work by suggesting that, in addition to academic and social adjustment, emotional adjustment and attachment to the university also play important roles. The four categories comprising this framework, measured by their Student Adaptation to College Questionnaire (SACQ), are outlined in Table 1. Although developed for face-toface contexts, this conceptual framework links with previously established models for online learning, such as the Community of Inquiry framework, where key components of online learning include social, cognitive, and teaching presence (Garrison, 2011).

Table 1

Defined Categories of Student Adjustment

\begin{tabular}{ll}
\hline \multicolumn{1}{c}{ Category } & \multicolumn{1}{c}{ Definition } \\
\hline Academic adjustment & $\begin{array}{l}\text { How well students manage the educational demands of the university } \\
\text { experience }\end{array}$ \\
Social adjustment & $\begin{array}{l}\text { How well students deal with interpersonal experiences at the } \\
\text { university (e.g., making friends, joining groups) }\end{array}$ \\
Emotional adjustment & $\begin{array}{l}\text { How well students maintain emotional equilibrium, particularly in the } \\
\text { face of adjustment stressors }\end{array}$ \\
Attachment & The degree of identification with and commitment to the university
\end{tabular}

Note. Based on Baker \& Siryk, 1999; Tinto, 1998.

Internationally, much work identifies that these four adjustment categories can predict academic performance and retention (Rienties et al., 2012), as highlighted by a recent meta-analysis of 237 studies and 44,668 students from around the world (Credé \& Niehorster, 2012). Specific to South Africa, Petersen, Louw, Dumont, and Malope (2009) used this model to evaluate the experiences of disadvantaged students, and found links between adjustment and performance. Sommer and Dumont (2011) also found that adjustment experiences could be explained by factors such as perceived stress or work overload. Similarly, Sennett, Finchilescu, Gibson, and Strauss (2003) considered the impact of demographic variables, such as race and gender, on adjustment experiences in South Africa and found that black African students had lower levels of social and emotional adjustment. More recently, Papageorgiou and Callaghan (2018) outlined that South African students' personality traits can influence their degree of academic adjustment. Altogether, these findings highlight adjustment as a key consideration for higher education students, with a broad range of demographic and institutional factors impacting their experiences.

However, much of this research was undertaken in face-to-face contexts and, to the best of our knowledge, no studies have replicated these findings with distance learners to understand how their 
experiences might differ. In particular, more work is needed from the Global South perspective, whereby students may have different experiences of agency, capital, and self-efficacy (Subotzky \& Prinsloo, 2011). Therefore, this study aimed to bring together these various strands of research to address the following research questions:

1. What are the adjustment experiences of distance learners in South African higher education?

2. What factors impact the adjustment experiences of distance learners in South African higher education?

\section{Methods}

\section{Setting and Procedure}

This research took place at UNISA in a first-year level course unit with undergraduate students studying for a Bachelor of Science degree in Mathematics and Programming in the College of Science, Engineering and Technology. This was a purposeful sample, as the academics teaching the selected courses volunteered to participate in a wider study as part of the International Distance Education and African Students (IDEAS) project. The data that supports the findings of this study will be available via UK data ReShare once the project is finished.

UNISA's modules are taught using a blended distance model, with digitally-supported materials and printed materials available for the many students with limited Internet access. All courses in the sample had an online presence in the learning management system, but online engagement was not required. Students were required to buy textbooks for self-study, while additional exercises or materials were hosted online. Pastoral support services were offered at the university by telephone, email, or face-toface by non-compulsory tutorial support programs at a range of regional centres. In terms of social connections among students, online tools such as an online forum and social media are frequently used to develop a student community. All programmes and examinations in this faculty are taught in English, although only a small percentage of students are native speakers. This means there are likely a range of competencies with English language across individual students, although there is no systematic data collection on this at the university.

\section{Participants}

All students in the selected programme were contacted via their university email address with a link to the online survey. Altogether, 320 students participated, which is a reasonable response rate of $11.77 \%$ (Nulty, 2008). The majority were male ( $\mathrm{n}=216,68 \%)$, which is in line with demographics in the programme. In terms of citizenship, 270 were South African (84\%) and 36 were international students (11\%) from 16 countries across Africa (14 declined to provide information about nationality). Most students were black African ( $\mathrm{n}=228,71 \%$ ), while 48 were white (15\%), 17 were Indian or Asian $(5 \%), 12$ were coloured (4\%), ${ }^{\mathrm{i}}$ and 5 declined to disclose their race. The majority of participants were non-native English speakers ( $\mathrm{n}=247,69 \%)$. Only $24 \%$ of students in this study $(\mathrm{n}=87)$ were full-time students, which is common in flexible distance learning contexts. Many participants had additional commitments beyond studying, including full-time $(\mathrm{n}=172,48 \%)$ or part-time $(\mathrm{n}=30,8 \%)$ work. Altogether, the sample is a reasonable representation of the student population in this programme. 


\section{Materials}

This research incorporated a mixed methods methodology (Creswell \& Plano Clark, 2011) using a questionnaire that included both quantitative and qualitative questions. As outlined in our Conceptual Framework section and by Baker and Siryk (1999), this study aimed to understand students' adjustments to the multifaceted transitions associated with studying at a distance from a South African institution. To measure these experiences and address research question one, the Student Adaptation to College Questionnaire (SACQ) was employed (Baker \& Siryk, 1999). SACQ measures students' experiences across four subscales, based on the categories defined in Table 1. The SACQ questionnaire has been previously used successfully in the South African higher education context (Davidowitz \& Schreiber, 2008; Papageorgiou \& Callaghan, 2018; Petersen et al., 2009; Sennett et al., 2003; Sommer \& Dumont, 2011). However, as UNISA students study at a distance and often have limited Internet access, we aimed to shorten the original instrument to ensure that it was fit for purpose in this context and to avoid questionnaire fatigue. Building on an extensive validation process of 1200 responses of students from nine universities in the Netherlands (Rienties et al., 2012), we selected the items with highest factor loadings from this previous work that were relevant for distance learning contexts, thereby reducing the questionnaire from 69 to 35 items. For more information about the scale and the validity and reliability of its shortened version, please see Rienties et al. (2012). Participants were asked to rate their agreement on a 1 to 9 Likert scale ( 1 = strongly disagree, $9=$ strongly agree). As this faculty teaches all course units and conducts all examinations in English, we also opted to conduct this study in English as it was the common university language that was most familiar to participants.

To assess the validity and appropriateness of the instrument in the South African distance learning context, the full instrument was piloted with 16 UNISA students using a think-aloud protocol, which indicated that questions were clear and relevant to students' experiences. Cronbach alphas of each scale also indicated good internal reliability (academic adjustment, $\alpha=.781$; social adjustment, $\alpha=.782$; emotional adjustment, $\alpha=.701$; and attachment, $\alpha=.845$ ). Additionally, the questionnaire was analysed using factor analysis, which indicated good fit for the four constructs.

As research question two focused on factors that impact distance learning experiences in South Africa, questions related to students' backgrounds and demographics were included. These included questions about gender, race, country of citizenship, access to resources required for study (e.g., Internet, computer, mobile phone), language, and employment status. Additionally, participants were asked two open-ended questions, which provided a more in-depth qualitative perspective: (a) Is there anything that has positively influenced your UNISA experience? and (b) Is there anything that has negatively affected your UNISA experience?

\section{Data Analysis}

For quantitative data, normality was assessed by a visual review of normal distribution curves and analysis of skewness/ kurtosis, to which all data was within the acceptable limits of +2.00 (Field, 2013). Interpretation was aided by coding categorical variables (i.e., gender, race, citizenship, English as first language, full-time student status, and access to various technologies) as dummy binary values. This allowed us to compare experiences of students from different backgrounds, for example, South African students compared to non-South African students. To compare SACQ scale scores with participants' demographic variables, bivariate analysis using Pearson's $r$ was conducted. Regression analyses were additionally calculated with each SACQ scale as the dependent variable and participants' background characteristics as independent variables. 
For qualitative open-ended responses, thematic analysis was conducted using the six-step protocol suggested by Braun and Clarke (2006). Altogether, 19 themes were identified by the researchers, which were clustered around the four SACQ scales to aid interpretation. Given that a large research team was involved in the qualitative analysis, steps were taken to compare our understandings of the codes and themes. First, after the codes were initially developed, a second member of the research team individually coded 50 responses to the questionnaire. Cohen's kappa was used to assess inter-rater reliability, which indicated good agreement $(\kappa=.869)$. Afterwards, the two researchers compared perspectives and made revisions to the codes. Next, a third member of the research team analysed a different selection of 50 responses using the revised codes. Cohen's kappa again indicated good agreement $(\kappa=776)$, which was confirmed through in-depth group discussions.

As a lens for our thematic qualitative analysis, we used a k-means cluster analysis to group participants based on their SACQ scores, as conducted in previous work by the authors (Mittelmeier et al., 2018). Cluster analysis is a method for sorting data into groups based on similar traits, in our case, SACQ scores. K-means cluster analysis was deemed appropriate for grouping participants based on their SACQ scores because the variables were numerical and on an interval scale (Everitt, Landau, Leese, \& Stahl, 2011). ANOVA F-value scores were compared as a proxy for cluster analysis, which determined that four clusters were the best fit for the data, as described in Table 2 (Field, 2013). Altogether, this approach allowed us to explore different types of student experiences across the qualitative data and to compare factors that may have impacted their adjustment.

Table 2

Clustering of Students Using K-Means Cluster Analysis

\begin{tabular}{llcccc}
\hline Cluster \# & \multicolumn{1}{c}{ Definition } & $\begin{array}{c}\text { Average } \\
\text { academic } \\
\text { adjustment }\end{array}$ & $\begin{array}{c}\text { Average social } \\
\text { adjustment }\end{array}$ & $\begin{array}{c}\text { Average } \\
\text { emotional } \\
\text { adjustment }\end{array}$ & $\begin{array}{c}\text { Average } \\
\text { attachment }\end{array}$ \\
\hline Cluster 1 & $\begin{array}{l}\text { Students who scored relatively high } \\
\text { on all four SACQ adjustment scales. }\end{array}$ & 7.10 & 6.91 & 6.85 & 8.24 \\
\hline Cluster 2 & $\begin{array}{l}\text { Students who scored relatively low } \\
\text { on all four SACQ adjustment scales. }\end{array}$ & 4.56 & 4.30 & 3.97 & 4.95 \\
\hline Cluster 3 & $\begin{array}{l}\text { Students who scored relatively high } \\
\text { on most SACQ scales, but scored } \\
\text { low on social adjustment. }\end{array}$ & 6.91 & 4.63 & 7.15 & 7.78 \\
\hline Cluster 4 & $\begin{array}{l}\text { Students who scored relatively low } \\
\text { on most SACQ scales, but scored } \\
\text { high on attachment. }\end{array}$ & 5.90 & 4.93 & 4.85 & 7.38 \\
\hline
\end{tabular}

\section{Results}

\section{Quantitative Results}

Average SACQ scores. In terms of research question one, Table 3 shows average scores for each SACQ scale, indicating that students felt generally positive about their distance learning experience. 
The lowest average scores were in relation to social and emotional adjustment, which is logical considering the absence of a physical campus community for distance learners. On average, participants also demonstrated a high level of attachment towards the university.

Table 3

Average SACQ Scale Scores

\begin{tabular}{lll}
\hline \multicolumn{1}{c}{ Scale } & M & SD \\
\hline Academic adjustment & 6.27 & 1.25 \\
Social adjustment & 5.40 & 1.44 \\
Emotional adjustment & 5.80 & 1.55 \\
Attachment & 7.33 & 1.42 \\
\hline
\end{tabular}

Note. Items were scored on a 1 to 9 scale.

However, there was strong variation among students, as evidenced by the large standard deviations for each scale (Table 3). An example of this wide variation is depicted graphically in Figure 1, which suggests there are additional factors impacting students' reflections on their distance learning experiences.

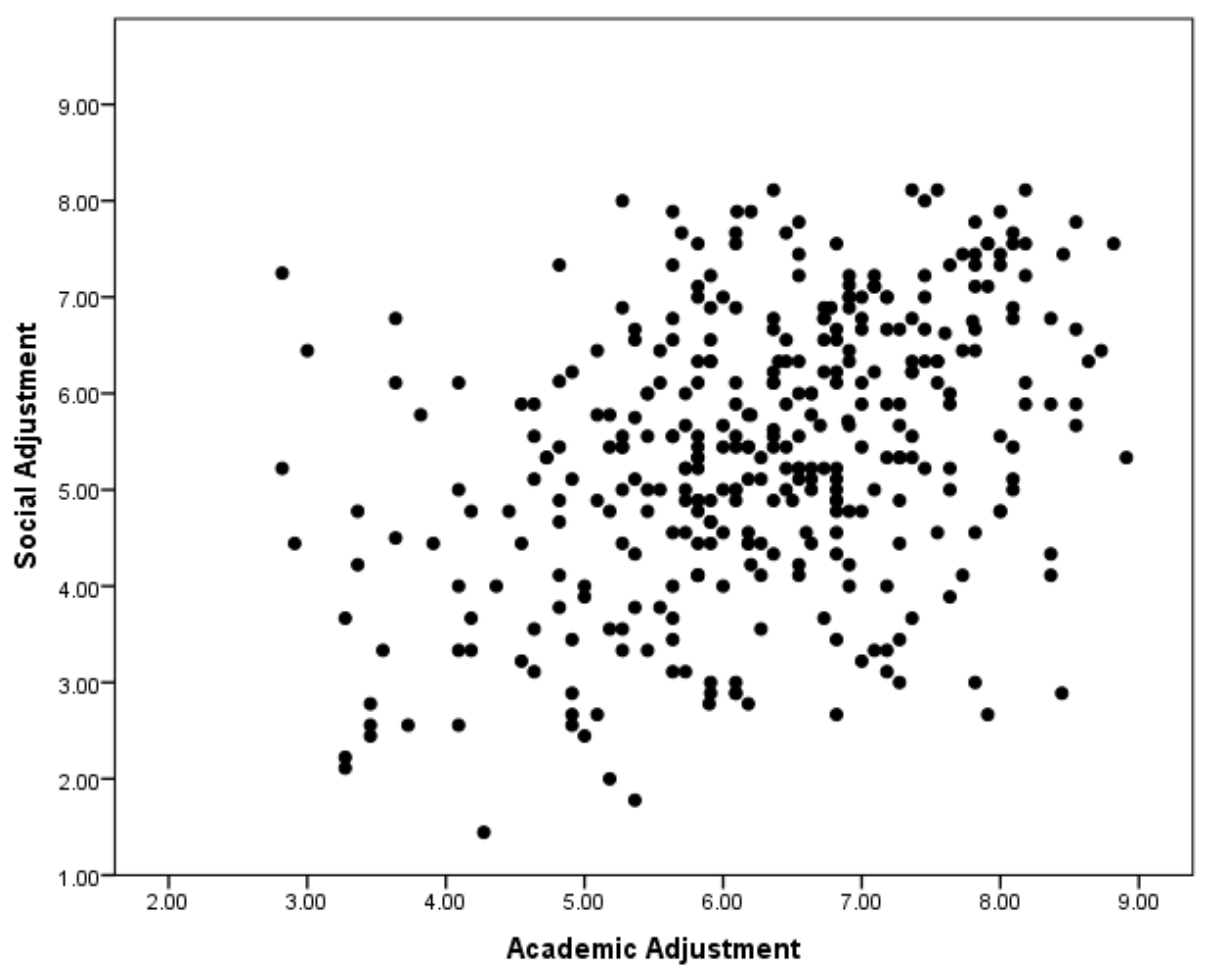

Figure 1. Scatterplot of SACQ academic and social adjustment scores (scored on a 1 to 9 scale). 
Correlation between SACQ scores and demographic variables. Bivariate analysis between the individual SACQ scores and various background and demographic variables was conducted using Pearson's $r$, which is highlighted in Table 4.

The strong correlations between the four SACQ scales highlighted that adjustment is multifaceted and often interlinked. This analysis also indicated relationships between demographic variables and the adjustment scales. For example, there was a negative correlation between gender and emotional adjustment, with women less likely to reflect positively on their emotional adjustment experiences. A relationship between race and adjustment was also found, with black African students more likely to reflect positively on their social adjustment and attachment to the university compared to students from other racial groups. As well, there was a weak and negative correlation between language and all four adjustment categories, meaning those who spoke English as their first language were more likely to reflect negatively on their university experiences.

In addition to demographic variables, access to resources was highlighted in Table 4 as an important factor in adjustment experiences, particularly in the area of academic and social adjustment. Positive correlations were found between academic adjustment and access to resources (including a computer, mobile phone, and Internet). Therefore, while distance learning had a moderating effect for issues such as race and language, class issues may still permeate the extent to which students feel academically adjusted to the demands of study. At the same time, there was a negative correlation between social adjustment and access to resources, meaning those with access to resources required for distance study reflected more negatively on their social experiences in distance learning. One reason for this could be that students without access to technologies were more likely to access computer laboratories in regional centres, thereby feeling more connected with a physical university community. Therefore, questions remain about what steps can be taken to socially integrate students who primarily work at home and away from a physical campus. 
Table 4

Bivariate Analysis of SACQ Scores and Demographic Variables

\begin{tabular}{|c|c|c|c|c|c|c|c|c|c|c|c|c|c|}
\hline & 1 & 2 & 3 & 4 & 5 & 6 & 7 & 8 & 9 & 10 & 11 & 12 & 13 \\
\hline 1. Academic adjustment & -- & -- & -- & -- & -- & -- & -- & -- & -- & -- & -- & -- & -- \\
\hline 2. Social adjustment & $.391^{* *}$ & -- & -- & -- & -- & -- & -- & -- & -- & -- & -- & -- & -- \\
\hline 3. Emotional adjustment & $.627^{* *}$ & $.324^{* *}$ & -- & -- & -- & -- & -- & -- & -- & -- & -- & -- & -- \\
\hline 4. Attachment & $.633^{* *}$ & $.408^{* *}$ & $.516^{* *}$ & -- & -- & -- & -- & -- & -- & -- & -- & -- & -- \\
\hline 5. Age & -.032 & .049 & .056 & .031 & -- & -- & -- & -- & -- & -- & -- & -- & -- \\
\hline 6. Gender & -.093 & -.003 & $-.237^{* *}$ & -.090 & $-.099+$ & -- & -- & -- & -- & -- & -- & -- & -- \\
\hline 7. Race: black African & $.094^{+}$ & $.217^{* *}$ & .065 & $.155^{* *}$ & $.098^{+}$ & -.019 & -- & -- & -- & -- & -- & -- & -- \\
\hline 8. South African & -.046 & -.041 & -.083 & -.056 & -.019 & .020 & $-.122^{*}$ & -- & -- & -- & -- & -- & -- \\
\hline 9. English as first language & $-.143^{*}$ & $-.142^{*}$ & $-.119^{*}$ & $-.135^{*}$ & -.012 & -.005 & $-.340^{* *}$ & $.109^{*}$ & -- & -- & -- & -- & -- \\
\hline 10. Full -time student & .082 & .035 & -.046 & .041 & $-.365^{* *}$ & .046 & -.031 & -.021 & .035 & -- & -- & -- & -- \\
\hline 11. Computer at home & $.125^{*}$ & -.087 & .086 & .008 & .085 & $-.105^{+}$ & .015 & .011 & .037 & -.081 & -- & -- & -- \\
\hline 12. Internet at home & .076 & -.061 & .003 & -.028 & .025 & -.024 & $-.167^{* *}$ & -.028 & .079 & .030 & $.487^{* *}$ & -- & -- \\
\hline 13. Mobile phone access & $.115^{*}$ & $-.104^{*}$ & .029 & .000 & .051 & -.014 & .022 & .010 & $.122^{*}$ & $-.106^{*}$ & $.425^{* *}$ & $.350^{* *}$ & -- \\
\hline 14. Quiet working space at home & $.113^{*}$ & $-.151^{* *}$ & $.090^{+}$ & .046 & -.044 & -.064 & $-.129^{*}$ & $-.098^{+}$ & .063 & .049 & $.372^{* *}$ & $.360^{* *}$ & $.463^{* *}$ \\
\hline
\end{tabular}

** $\mathrm{p}<.01$

$* \mathrm{p}<.05$

$+\mathrm{p}<.1$ 
Regression analysis. These findings were further unpacked using regression analyses with the SACQ scales as dependent variables and demographic information as independent variables, as outlined in Table 5. These findings, again, highlighted that there are demographic influences in the ways in which students reflect upon their distance learning experiences. In particular, significant factors in the regression analyses included language, race, and gender.

Table 5

Regression Analyses of SACQ Scales and Demographic Variables (Standardised Beta Coefficients)

\begin{tabular}{lllll}
\hline & $\begin{array}{c}\text { Academic } \\
\text { adjustment }\end{array}$ & $\begin{array}{c}\text { Social } \\
\text { adjustment }\end{array}$ & $\begin{array}{c}\text { Emotional } \\
\text { adjustment }\end{array}$ & Attachment \\
\hline Age & -.028 & .058 & .020 & .043 \\
Gender & -.085 & -.006 & $-.222^{* *}$ & -.082 \\
Race: Black African & .049 & $.200^{* *}$ & .034 & $.170^{*}$ \\
South African & -.074 & .012 & $-.110^{*}$ & -.072 \\
English as first language & $-.163^{* *}$ & -.067 & $-.127^{*}$ & -.088 \\
Full-time student & .096 & .056 & -.022 & .070 \\
Computer at home & .051 & -.033 & .052 & .013 \\
Internet at home & .022 & .050 & -.038 & -.012 \\
Mobile phone & .082 & -.052 & -.012 & .006 \\
Quiet working space at home & .047 & -.089 & .100 & .098 \\
& & & & .035 \\
\hline Adjusted R ${ }^{2}$ & .035 & .059 & .066 & \\
\hline
\end{tabular}

$* * \mathrm{p}<.01$

$* \mathrm{p}<.05$

In line with previous work using the SACQ in South Africa (Petersen et al., 2009), demographic variables could explain only a relatively small percentage of variation among participants. This means that other experiences have interlinked or parallel influences on students' adjustment experiences. To illuminate this for research question two, the next section summarises themes from the survey's open-ended questions to provide a richer, qualitative understanding of the quantitative findings.

\section{Qualitative Results}

Flexibility of distance learning. Considering the high percentage of part-time learners and those with full- or part-time work commitments, many participants across the four clusters positively reflected on how the flexibility of distance learning allowed them to incorporate education into their existing lives and commitments, indicating a relatively universal perspective. 
Studying at UNISA for education gives me enough time, as I'm currently working as a teacher. The time I'm given for my assignments is also reasonable. (Participant 128, female, South African student, Cluster 3)

They gave us many chances to do our work, so any challenges in my life won't cause me to miss most of my activities. (Participant 163, male, South African student, Cluster 4)

For some students, this flexibility was key to accessing higher education and developing (perceived) social mobility. Such comments were particularly prevalent from students in Cluster 4 (i.e., those with high attachment to the university, but relatively low academic, social, or emotional adjustment). Overall, this indicated that, despite perceived adjustment difficulties, appreciation of the distance learning format supports students' overall attachment to the university.

UNISA gives us the opportunity to study part-time and gives us access to education. The model is a good model that allows for greater access to education. (Participant 27, male, international student, Cluster 4)

I've managed to make a living while I'm studying at UNISA. It's a well-recognised institution. I found my previous job due to the fact that I was studying with UNISA. Since I am from a disadvantaged family, I found it easy to believe that I could still reach my goal. (Participant 47, male, South African student, Cluster 4)

In our quantitative findings, most students demonstrated relatively high attachment to the university, despite academic, social, and emotional adjustment hurdles. These qualitative responses shed light on this phenomenon, outlining the role of distance learning in providing an alternative route to higher education.

Independent studying and learning. Participants noted that distance learning required a high level of independent studying and self-sufficiency. On the one hand, some participants noted that studying independently helped them gain new skills and insights, such as time management, selfreliance, and independence. This was particularly prevalent for Cluster 1students (i.e., those who scored relatively high on all four adjustment scales), demonstrating more positive reflection from those with better adjustment experiences.

My time managed [sic] skill has improved, also with the commitment towards my studies. It has surely taught me to commit also to other things than my studies. (Participant 88, male, South African student, Cluster 1)

On the other hand, other students frequently cited frustrations with learning independently, including difficulties understanding tasks on their own or lack of timely feedback. This was more frequently demonstrated by those with lower adjustment scales, such as Cluster 2 (i.e., those with relatively low adjustment scores in all four categories).

I struggle to motivate myself to work. When I have trouble with something, it's difficult to get in contact with someone who can help me. (Participant 256, female, South African student, Cluster 2) 
Therefore, one reason for the variation among clusters (i.e., those with similar SACQ score patterns) could be coping mechanisms related to students' comfort and competence with self-study in absence of a physical classroom.

Access to resources and technology. In our quantitative findings, access to resources required for study (e.g., computer, mobile phone, Internet) was linked to positive academic adjustment. This was also frequently discussed by participants in the qualitative open-ended comments. In particular, many participants noted issues with receiving or accessing course materials. This was especially prevalent among students across the four clusters who were living in rural communities or outside South Africa, which helps clarify some of the underlying issues that affect students' access to resources.

Not having my study material on time. I ended up not submitting my semester 1 assignments and also requesting a book from the library not knowing it'll take weeks before being delivered and by that time I no longer needed. (Participant 262, female, South African student, Cluster 2)

In some cases, lack of access to materials was cited as a major disruption in students' learning or ability to continue with the course. These findings were more frequent for those with lower overall SACQ scores (Clusters 2 and 4), indicating access to materials played an important role in the adjustment challenges experienced by some students.

I had to cancel drawing because I couldn't get the textbook and paying for school myself is a lot to loose [sic], 2500, which I have to pay again next semester. (Participant 249, female, South African student, Cluster 2)

I have find it difficult to do some of my assignments due to the limited textbooks. I have failed to submit my assignment because only the book late and I am not going to write exam for one of my subjects due to shortage of books. (Participant 207, female, South African student, Cluster 4)

Participants in these clusters also explained that their adjustment experiences were impacted by access to resources.

Studying online was very difficult for me because most of the time I don't get access to Internet, because UNISA labs are always full and I'm not using a smartphone. (Participant 260, female, South African student, Cluster 2)

Altogether, these findings highlight inequalities in access to materials required for study, which has, in turn, impacted students' adjustment experiences in distance learning.

Physical distance. Although UNISA does operate regional centres and occasionally holds optional in-person tutorials or practical sessions, it was frequently noted that not all participants had the ability to travel to or attend these sessions. This was particularly the case for those across the four clusters who live in rural areas or at a long distance from centres, and those with work or family commitments. Ability to pay for transportation to regional centres was also frequently noted as a concern. 
I cannot attend tutorial because they start late and I'm staying far from the campus. I did not attend my practical at Florida campus because I can't afford the transport and accommodation that side. (Participant 13, unknown gender or nationality, Cluster 2)

This physical distance also had implications for whether students felt socially connected with other students. Perhaps one explanation for variations in social adjustment scores, therefore, could be varying levels of physical isolation from university environments. After all, this was particularly prevalent for those in clusters with relatively low social adjustment.

I would say that it is hard to build relationships with other students if you are not close to any regional office. I wish there was an easier way. (Participant 113, male, South African student, Cluster 4)

The fact that we are not given a class list with students' details or perhaps something like an online class, influences one's morale and confidence in the subject. (Participant 184, female, South African student, Cluster 4)

While access to physical buildings was not a prerequisite for distance learners, students in low SACQ score clusters often noted frustration with communicating with the university or their lecturers.

Some subjects and lecturers are excellent, a lot of communication, and nearly no support needed due to just communicating. Others you go through an entire semester with unanswered questions and unclarity [sic]. (Participant 200, female, South African student, Cluster 2)

Altogether, these findings outline the physical isolation of distance education as a common source of frustration for some students, which impacted their adjustment experiences.

Fees and funding. The open-ended comments revealed that tuition fees were a common source of stress and frustration for participants. In particular, participants noted burdens of self-funding and paying for fees not covered by the National Student Financial Aid Scheme (NSFAS). These concerns were prevalent across all four clusters of SACQ scores.

Financial support makes me lose my courage because even though I am about to complete my degree but I sometimes feel threatened by financial aid. (Participant 69, male, South African student, Cluster 4)

NSFAS did not pay for all my tuition fee and since I do not have parents, no one can buy for me and I'm even struggling for money to come to school. (Participant 236, female, South African student, Cluster 1)

For international students, there were additional stressors related to paying for courses from abroad. For example:

The only worry now is the method of payment. I know the favorite method is through credit card but this is not working in Uganda where I come from yet. (Participant 126, male, international student, Cluster 3) 
Altogether, financial stressors appeared prevalent for many students across all adjustment categories. This links with our suggestion in the quantitative findings that class may play an important role in the ways in which students feel adjusted to distance learning.

\section{Discussion}

The rise in popularity of distance education in South Africa, combined with the comparative lack of research into distance students' adjustment experiences, highlights a critical gap in current knowledge. This present study aimed to address this by examining students' adjustment experiences at UNISA, one of the largest distance education providers in the world. In doing so, the study explored: (a) contributing demographic variables affecting students' adjustment, and (b) factors that positively and negatively impacted their distance learning experience.

\section{Research Question One}

Our cluster analysis of SACQ scores indicated there was a wide range of adjustment experiences, which could be divided into four categories (highlighted in Table 2). The results further suggested that all four categories of adjustment could be partially explained by demographic factors. However, the variation in adjustment among demographic groups had only low to medium effect sizes (between 3.5\% and 6.6\%). This initially indicated that other factors outside of demographics more strongly influence students' experiences.

The largest demographic contributors to differences in adjustment levels were language and race. In both instances, adjustment patterns were against the 'norm', with more traditionally marginalised populations demonstrating better adjustment. For instance, we found in our bivariate and regression analyses that students who were not native English speakers were better adjusted across the four categories we measured. This is interesting, considering less than $10 \%$ of the South African population are native English speakers (Statistics South Africa, 2012) and native English speakers represent historically privileged groups (i.e., those with white British colonial heritage). In the same analyses, race was one of the strongest predictors in our findings, particularly in regards to social adjustment and attachment to the university. Black African students in our study reported significantly better adjustment compared to students from other racial groups. This is in contrast to previous research in face-to-face contexts in South Africa, whereby black African students were found to be less adjusted compared to white students (Sennett et al., 2003). Together, perhaps these findings speak to the role that distance education plays in South Africa, operating as an alternative route to accessing higher education for historically marginalised or underprivileged groups. This is further supported by the overall strong attachment to the university across our four student clusters, including the sizeable Cluster 4, namely students with overall low adjustment but nevertheless strong attachment. In this way, it seems that despite the struggles associated with distance education and dissatisfaction with the experience, some students have a strong attachment to the university that is largely linked to their appreciation of increased access to higher education through distance learning. Therefore, additional research might further unpack this notion through an explicit investigation of the role and function of distance learning to the lives of students in Global South contexts. 


\section{Research Question Two}

Our second research question considered other factors beyond demographics that impacted students' distance learning experiences. In this regard, all clusters of students reported in the qualitative openended questions that the main challenges they faced were in relation to fees and funding, along with timely access to resources required for study (e.g., books, learning materials, technology, tutors) in line with work by Lekena and Bayaga (2018). This, as also found in prior research (Halabi et al., 2014; Swart, 2015), outlines the important role of class in students' distancelearning experiences. For example, ability to pay university fees and have access to required study materials were the main points that distinguished students among the different SACQ clusters in our study. The most dissatisfied group of students-Cluster 2, who showed the lowest adjustment and attachment-struggled most with funding and access to resources, combined with difficulties related to independent studying and feelings of isolation. Altogether, these findings suggest that when designing modules, distancelearning institutions, particularly those serving students in the Global South, should be mindful of the accessibility of resources, technologies, and activities (see also our prior work: Mittelmeier et al., 2018).

The results from the open-ended questions supported the notion that students' academic, social, and emotional adjustments were largely influenced by the positive and negative experiences they had during their initial period of studying at the university. This further demonstrates that the importance of early experiences outlined in face-to-face contexts (Leibowitz et al., 2009; Upcraft \& Gardner, 1999; Wilcox et al., 2005) similarly applies in distance settings. However, the wide range of adjustment experiences we discovered suggests students had varying levels of resilience, study skills, and coping mechanisms. These findings are in line with previous research by Sommer and Dumont (2011), who found that adjustment experiences in face-to-face contexts could be explained by factors such as perceived stress or work overload. In this regard, our findings imply strong inequalities among groups of students in terms of physical isolation, social community development, and access to timely feedback. Thus, the challenges existing across different levels in distance learning (Subotzky \& Prinsloo, 2011) seem to disproportionately affect students with fewer resources (e.g., transportation, technology, finances, time). As such, this study has prompted important questions for future research around distance education and privilege, keeping in mind that access to higher education is as much about the ability to succeed as it is the ability to enrol.

\section{Limitations and Conclusions}

This study has provided a macro-level analysis of distance education students' experiences while studying through a South African institution and has highlighted suggested areas for future research. In doing so, several limitations are recognised. For one, this research utilises self-report measurements and we note that more research will be necessary in the future to unpack how these reflective experiences relate to measurable learning behaviours. We also recognise that students in our sample were studying in a STEM field and experiences may vary for students in other fields, which is a clear area for additional research. Finally, we recognise that the student population at UNISA is exceptionally diverse, including thousands of international students living across Africa and the world, and more research is needed to unpack the experiences of their particular situations. Nonetheless, this research has provided an important starting point for conversations around supporting distancelearners' adjustment experiences and the role of distance learning in students' lives. In particular, we have outlined the important role of issues such as race and class in influencing South African distance students' adjustment experiencesan area in clear need of further research and conceptualisation, both within and outside of South Africa. 


\section{Acknowledgements}

The IDEAS project is funded by the Newton Grant and supported by the Economic and Social Research Council [grant number: ES/P002161/1]; and the National Research Foundation [grant number: UTSA160329161196]. The IDEAS project involved an interdisciplinary international team of researchers. The authors would like to acknowledge the varied contributions of all the other team members involved in the wider project. 


\section{References}

Altbach, P. G., Reisberg, L., \&Rumbley, L. E. (2009). Trends in global higher education: Tracking an academic revolution. Paris, France: UNESCO.

Badat, S. (2005). South Africa: Distance higher education policies for access, social equity, quality, and social and economic responsiveness in a context of the diversity of provision. Distance Education, 26(2), 183-204. doi:10.1080/01587910500168843

Baker, R. W., \& Siryk, B. (1999). SACQ student adaptation to college questionnaire. Los Angeles, CA: Western Psychological Services.

Baxter, J . A. (2012). Who am I and what keeps me going? Profiling the distance learning student in higher education. The International Review of Research in Open and Distributed Learning, 13(4), 107- 129. doi:10.19173/ irrodl.v13i4.1283

Bozalek, V., \& Ngambi, D. (2015). The context of learning with technology. In W. R. Kilfoil (Ed.), A contextualised view of learning with technology in higher education. Pretoria, South Africa: University of South Africa.

Braun, V., \& Clarke, V. (2006). Using thematic analysis in psychology. Qualitative Research in Psychology, 3(2), 77-101. doi:10.1191/ 1478088706qp063oa

Brown, M., Hughes, H., Keppell, M., Hard, N., \& Smith, L. (2015). Stories from students in their first semester of distance learning. The International Review of Resrach in Open and Distributed Learning, 16(4). doi:10.19173/irrodl.v16i4.1647

Credé, M., \&Niehorster, S. (2012). Adjustment to college as measured by the Student Adaptation to College Questionnaire: A quantitative review of its structure and relationships with correlates and consequences. Educational Psychology Review, 24(1), 133- 165. doi:10.1007/ s10648-0119184-5

Creswell, J . W., \& Plano Clark, V. L. (2011). Designing and conducting mixed methods research (2nd ed.). London, United Kingdom: SAGE.

Daniels, V. (2017). The effects of family structure and autonomy-supportive parenting on the adjustment of first year university students (Doctoral thesis, University of the Western Cape). Retrieved from http:// etd.uwc.ac.za/ xmlui/handle/ 11394/ 5623

Davidowitz, B., \& Schreiber, B. (2008). Facilitating adjustment to higher education: Towards enhancing academic functioning in an academic development programme. South African J ournal of Higher Education, 22(1), 191- 206.

Department of Higher Education and Training. (2012). South African higher education open data. Retrieved from https:// www.chet.org.za/ data/ sahe-open-data 
Department of Higher Education and Training. (2014). Policy for the provision of distance education in South African universities in the context of an integrated post-school system. Retrieved from http:// www.saide.org.za/sites/default/files/37811_gon535.pdf

Everitt, B. S., Landau, S., Leese, M., \& Stahl, D. (2011). Cluster analysis (5th ed.). West Sussex, United Kingdom: Wiley.

Faragher, L., \& Huijser, H. (2014). Exploring evidence of higher order thinking skills in the writing of first year undergraduates. The International J ournal of the First Year in Higher Education, 5(2), 33- 44 .

Field, A. (2013). Discovering statistics using IBM SPSS Statistics (4th ed.). London: SAGE.

Garrison, D. R. (2011). E-learning in the 21st century: A framework for research and practice. London, United Kingdom: Routledge.

Halabi, A. K., Essop, A., Carmichael, T., \& Steyn, B. (2014). Preliminary evidence of a relationship between the use of online learning and academic performance in a South African first-year university accounting course. Africa Education Review, 11(2), 164- 182.

doi:10.1080/ 18146627.2014.927148

J ordaan, J . (2016). Exploring first-year students' demands from the perspectives of student support structures: A world café study (Doctoral thesis, North-West University). Retrieved from https:// repository.nwu.ac.za/handle/ 10394/25547

Kahu, E. R., \&Nelson, K. (2018). Student engagement in the educational interface: Understanding the mechanisms of student success. Higher Education Research \& Development, 37(1), 58- 71. doi:10.1080/07294360.2017.1344197

Leibowitz, B., Van der Merwe, A., \& Van Schalkwyk, S. (2009). Focus on first year success: Perspectives emerging from South Africa and beyond. African Sun Media. doi:10.18820/9781920338220/00

Lekena, L. L., \& Bayaga, A. (2018). Trend analysis of first year student experience in university. South African J ournal of Higher Education, 32(2), 157- 175. doi: 10.20853/32-2-1934

Mahlangu, T. P., \& Fraser, W. J . (2017). The academic experiences of grade 12 top achievers in maintaining excellence in first-year university programmes. South African J ournal of Higher Education, 31(1), 104-118. doi: 10.20853/31-1-812

McGhie, V. (2017). Entering university studies: Identifying enabling factors for a successful transition from school to university. Higher Education, 73(3), 407-422. doi:10.1007/ s10734-016-0100-2

McKay, T. M. (2016). Do tutors matter? Assessing the impact of tutors on first-year academic performance at a South African university. J ournal of Student Affairs in Africa, 4(1), 53-64. doi: 10.14426/jsaa.v4i1.144 
Meier, C. (2007). Enhancing intercultural understanding using e-learning strategies. South African J ournal of Education, 27(4) 655-671.

Mittelmeier, J ., Long, D., Cin, F. M., Reedy, K., Gunter, A., Raghuram, P., \& Rienties, B. (2018). Learning design in diverse institutional and cultural contexts: Suggestions from a participatory workshop with higher education professionals in Africa. Open Learning: The J ournal of Open, Distance and e-Learning, 33(3), 250-266. doi:10.1080/ 02680513.2018.1486185

Mittelmeier, J., Rienties, B., Tempelaar, D., \&Whitelock, D. (2018). Overcoming cross-cultural group work tensions: Mixed student perspectives on the role of social relationships. Higher Education, 75(1), 149-166. doi:10.1007/ s10734-017-0131-3

Nulty, D. D. (2008). The adequacy of response rates to online and paper surveys: What can be done? Assessment \& Evaluation in Higher Education, 33(3), 301- 314. doi:10.1080/02602930701293231

Olivier, B. (2016). The impact of contact sessions and discussion forums on the academic performance of open distance learning students. The International Review of Research in Open and Distributed Learning, 17(6). doi:10.19173/irrodl.v17i6.2493

Papageorgiou, E., \& Callaghan, C. W. (2018). Personality and adjustment in South African higher education accounting studies. South African J ournal of Accounting Research, 32(2-3), 189204. doi:10.1080/ 10291954.2018.1442649

Petersen, I-h., Louw, J ., Dumont, K., \&Malope, N. (2009). Adjustment to university and academic performance among disadvantaged students in South Africa. Educational Psychology, 29(1), 99- 115. doi:10.1080/01443410802521066

Rienties, B., Beausaert, S., Grohnert, T., Niemantsverdriet, S., \& Kommers, P. (2012). Understanding academic performance of international students: The role of ethnicity, academic and social integration. Higher Education, 63(6), 685-700. doi:10.1007/s10734-011-9468-1

Sennett, J ., Finchilescu, G., Gibson, K., \& Strauss, R. (2003). Adjustment of black students at a historically white South African university. Educational Psychology, 23(1), 107- 116. doi:10.1080/01443410303219

Sommer, M., \& Dumont, K. (2011). Psychosocial factors predicting academic performance of students at a historically disadvantaged university. South African J ournal of Psychology, 41(3), 386395.

Spady, W. G. (1970). Dropouts from higher education: An interdisciplinary review and synthesis. Interchange, 1(1), 64- 85. doi:10.1007/bf02214313

Statistics South Africa. (2012). Census 2011: Census in brief. Retrieved from https:// www.statssa.gov.za/ publications/ P03014/P030142011.pdf 
Subotzky, G., \& Prinsloo, P. (2011). Turning the tide: A socio-critical model and framework for improving student success in open distance learning at the University of South Africa. Distance Education, 32(2), 177-193. doi:10.1080/ 01587919.2011.584846

Swart, A. J . (2015). Student usage of a learning management system at an open distance learning institute: A case study in electrical engineering. International J ournal of Electrical Engineering Education, 52(2), 142- 154. doi:10.1177/0020720915575925

Tessmer, M., \& Richey, R. C. (1997). The role of context in learning and instructional design. Educational Technology Research and Development, 45(2), 85- 115. doi:10.1007/ bf02299526

Tinto, V. (1975). Dropout from higher education: A theoretical synthesis of recent research. Review of Educational Research, 45(1), 89- 125.

Tinto, V. (1998). Colleges as communities: Taking research on student persistence seriously. Review of Higher Education, 21(2), 167- 177.

Upcraft, M. L., \& Gardner, J . N. (1999). The freshman year experience. Helping students survive and succeed in college. San Francisco, CA: J ossey-Bass.

Wilcox, P., Winn, S., \& Fyvie-Gauld, M. (2005). 'It was nothing to do with the university, it was just the people': The role of social support in the first-year experience of higher education. Studies in Higher Education, 30(6), 707- 722. doi:10.1080/ 03075070500340036

i These four racial categories are defined by the South African government and asked of students in response to post-1994 legislation and regulatory frameworks. 